Gut, 1972, 13, 965-969

\title{
Dipeptide absorption in man
}

\author{
M. D. HEllier, C. D. HOLDSWORTH ${ }^{1}$, I. MCCOLL, AND D. PERRETT \\ From the Departments of Medicine, Surgery, and Gastroenterology, St Bartholomew's Hospital, London, \\ and St Leonard's Hospital, London
}

SUMMARY A quantitative perfusion method has been used to study intestinal absorption of two dipeptides-glycyl-glycine and glycyl-L-alanine-in normal subjects. In each case, the constituent amino acids were absorbed faster when presented as dipeptides than as free amino acids, suggesting intact dipeptide transport. During absorption constituent amino acids were measured within the lumen and it is suggested that these represent amino acids which have diffused back to the lumen after absorption as dipeptide.

Portal blood analyses during absorption of a third dipeptide, glycyl-L-lysine, have shown that this dipeptide, known to be transported intact from the intestinal lumen, is hydrolysed to its constituent amino acids before it reaches portal venous blood.

We have recently described the use of a quantitative perfusion method for investigating dipeptide absorption from human jejunum, and have reported results of absorption studies of two lysine-containing dipeptides in normal and cystinuric subjects (Hellier, Holdsworth, Perrett, and Thirumalai, 1972). The results suggest that glycyl-L-lysine and L-lysyl-L-lysine are transported from the lumen of the jejunum intact and are thus able to overcome the transport defect found in cystinuria for dibasic amino acids. Good evidence for intact dipeptide transport in man had previously been obtained by the less direct method of the oral load test, measuring the appearance of absorbed substrate in the plasma. Using this method, Craft, Geddes, Hyde, Wise, and Matthews (1968) had produced evidence that glycyl-glycine was absorbed from the lumen intact. Asatoor, Cheng, Edwards, Lant, Matthews, Milne, Navab, and Richards (1970), as a result of studying patients with Hartnup disease, have also concluded that at least some dipeptides enter the mucosal cell intact, and that by this mechanism amino acids can be absorbed in patients with an intestinal amino acid transport defect.

However, knowledge of dipeptide absorption in man is still scanty, and dipeptides are not all handled alike, differing, for example, in the extent to which free amino acids appear in the lumen during absorption (Hellier et al, 1972). In this paper we have

1 Please address requests for reprints to Dr C. D. Holdsworth, Clinical Research Institute, Royal Infirmary, Sheffield 56 3DA.

Received for publication 4 October 1972. studied two dipeptides of glycine looking for further evidence of intact transport and assessing the degree of back diffusion. In addition, portal blood has been analysed for evidence of intact dipeptide transport across the mucosa.

\section{Methods}

PERFUSION STUDIES

Absorption of two dipeptides and of the constituent amino acids was studied by a jejunal perfusion technique in healthy young male volunteers, whose ages ranged from 19 to 38 years. Of the two dipeptides chosen, glycyl-glycine has been studied previously, and there is evidence from in-vitro work in animals and oral load studies in man to suggest that this dipeptide is transported intact from the lumen. Absorption of the second dipeptide, glycylL-alanine, has not previously been studied in man or animals.

Absorption was measured over a $30 \mathrm{~cm}$ length of upper jejunum using a modified double-lumen tube. The tube incorporates a proximal occlusive balloon which prevents reflux of perfused solutions proximal to the infusion site and contamination of the test segment by secretions from higher up the bowel. Solutions being studied were perfused at a constant rate of $15 \mathrm{ml}$ a minute down one lumen of the tube, entering the bowel at a point a little beyond the duodeno-jejunal flexure. Samples were collected via the second lumen using continuous syphonage from a point $30 \mathrm{~cm}$ further down the bowel. Correc- 
tion for volume change due to water movement was made using the non-absorbable marker polyethylene glycol (PEG). The method for calculation of results has been described previously (Hellier, Perrett, and Holdsworth, 1970).

PORTAL BLOOD ANALYSIS

Jejunal absorption studies were performed in two patients undergoing abdominal operation, in order to determine whether the dipeptide glycyl-L-lysine reached the portal blood intact. This dipeptide was chosen on account of the strong evidence from perfusion studies that it was transported intact from the lumen (Hellier et al, 1972). As previously, the dipeptide was studied at a concentration of $4.2 \mathrm{mM}$. In each patient the nature of the study was explained before operation and permission obtained by some person other than the surgeon or investigator. Patients were chosen who were to undergo laparotomy but in whom there was no small bowel pathology. At operation, a $30 \mathrm{~cm}$ segment of jejunum was isolated between two non-crushing clamps. An initial sample of blood was taken from a venous radical draining the loop. Fifty ml of dipeptide solution was injected into the loop. After 10 minutes a further sample of venous radical blood was taken, together with an aspirate from the jejunal loop. Blood samples and jejunal aspirate were analysed for amino acids and dipeptides. Volume change in the loop was measured as previously using PEG.

\section{CHEMICAL METHODS}

Amino acids and dipeptides were estimated by ion exchange chromatography using a standard Technicon amino acid analyser. Polyethylene glycol was measured by the method of Hydén (1955), turbidity being determined using a Unicam spectrophotometer 1300.

\section{Results}

PERFUSION RESULTS

In each case, absorption of the dipeptide was compared with that of the equivalent amount of free amino acid.

\section{Glycyl-glycine (Fig. 1)}

The following solutions were each studied in six subjects: A, glycyl-glycine $10 \mathrm{mM}, \mathrm{B}$, glycine 20 $\mathrm{mM}, \mathrm{C}$, glycyl-glycine $25 \mathrm{mM}$, and $\mathrm{D}$, glycine 50 mM.

The concentrations are all below the $\mathrm{Kt}$ for glycine, which using a similar method was $76 \mathrm{mM}$ (Fleshler, Butt, and Wismar, 1966).

At both concentrations studied, glycine was

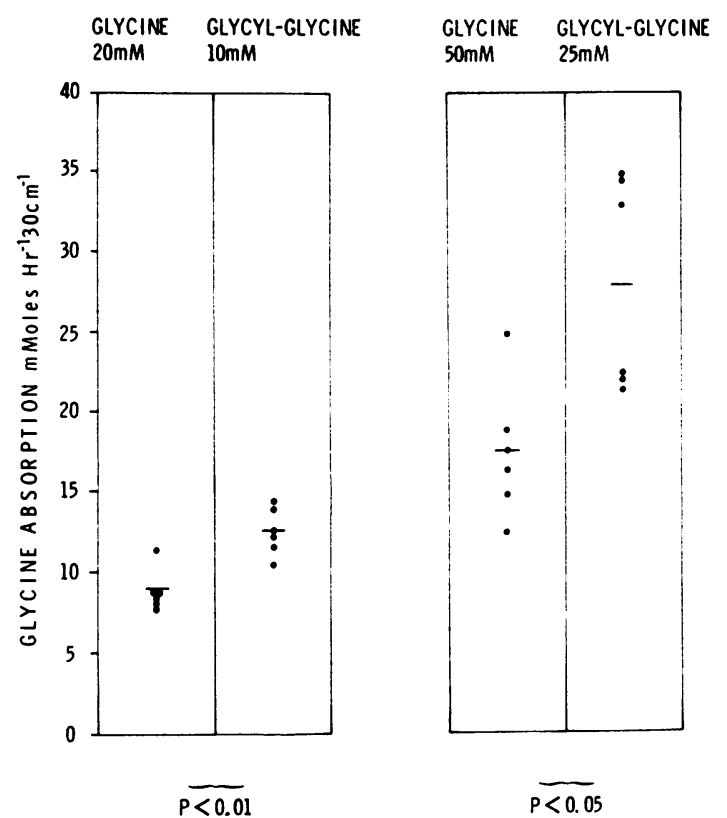

Fig. 1 Absorption of glycine in six normal subjects when perfused either as free amino acid or as the dipeptide glycyl-glycine. The P value was determined by Student's unpaired t test.

absorbed significantly faster when presented as dipeptide than as free amino acid.

Glycyl-L-alanine (Fig. 2)

The following solutions were each studied in six subjects: A, glycyl-L-alanine $10 \mathrm{mM}, \mathrm{B}$, glycine $10 \mathrm{mM}+\mathrm{L}$-alanine $10 \mathrm{mM}, \mathrm{C}$, glycine $10 \mathrm{mM}$, and $\mathrm{D}$, L-alanine $10 \mathrm{mM}$.

These concentrations are also all below the $K_{t}$ for either amino acid, the $K_{t}$ for alanine studied by a similar method being $36 \mathrm{mM}$ (Fleshler, Butt, and Wismar, 1966).

Both glycine and alanine were absorbed from the lumen more rapidly in every subject studied when presented as the dipeptide than as free amino acids. This suggests that this dipeptide too is absorbed intact from the lumen. It is of interest that although free glycine was absorbed significantly more slowly than free alanine $(P<0.02$ Student's $t$ test for paired data), this difference was not seen when these amino acids were absorbed from the dipeptide solution.

\section{BACK DIFFUSION}

\section{Glycyl-glycine}

During absorption of glycyl-glycine, free glycine, but no other amino acid, was detected within the 


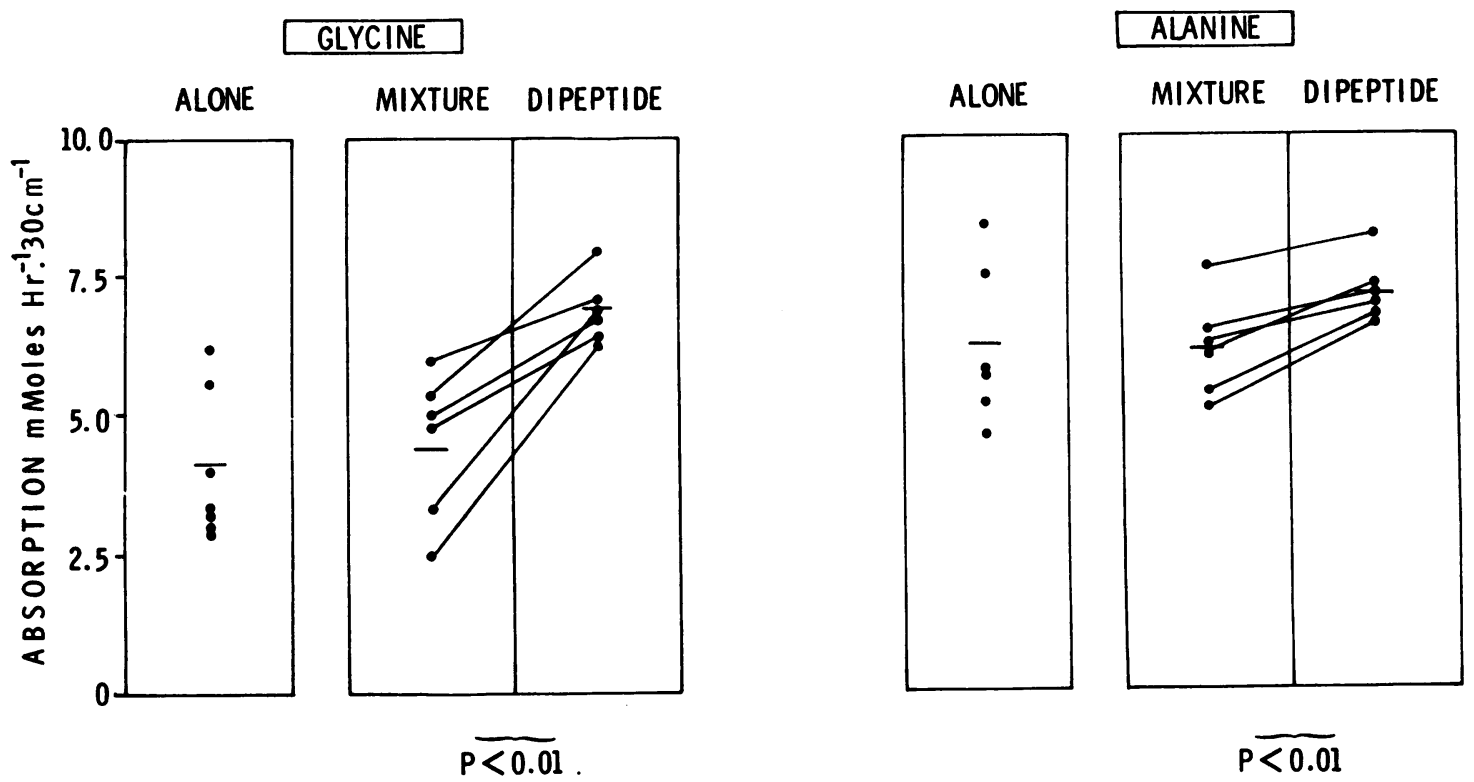

Fig. 2 Comparison of absorption rates of glycine and alanine in six normal subjects perfused either as a mixture or as the dipeptide. Absorption figures for the amino acids perfused alone in a different group of normal subjects are shown for comparison in the left-hand columns.

All solutions were studied at a concentration of $10 \mathrm{mM}$.

$\mathrm{P}$ values were determined by Student's paired $t$ test.

lumen. During $10 \mathrm{mM}$ glycyl-glycine perfusion, quantities of glycine varying between 415 and 1116 (mean 698) $\mu$ moles $\mathrm{Hr}^{-1} 30 \mathrm{~cm}^{-1}$ appeared within the lumen. This is $2 \cdot 3-6.2 \%$ (mean $3 \cdot 8$ ) of the amount administered as dipeptide. During $25 \mathrm{mM}$ glycyl-glycine perfusion, the amount of free glycine varied between 963 and 2970 (mean 1977) $\mu$ moles $\mathrm{Hr}^{-1} 30 \mathrm{~cm}^{-1}$, equivalent to $1.9-5.9 \%$ (mean 4.4 ) of the glycine administered as dipeptide.

\section{Glycyl-L-alanine}

Free glycine and alanine were both found within the lumen during perfusion of $10 \mathrm{mM}$ glycyl-Lalanine. The amount of glycine varied between 125 and 450 (mean 290) $\mu$ moles $\mathrm{Hr}^{-1} 30 \mathrm{~cm}^{-1}$ and of alanine between 70 and 150 (mean 116) $\mu$ moles $\mathrm{Hr}^{-1} 30 \mathrm{~cm}^{-1}$. These figures represent $1 \cdot 4-5 \cdot 0$ (mean
3.2) and 0.8-1.7 \% (mean 1.3 ) respectively of the amount of amino acid administered as dipeptide.

PORTAL BLOOD STUDY (TABLE I)

In this study, the dipeptide glycyl-L-lysine was used. Fasting portal blood levels were measured in only one of the two patients for technical reasons. Two samples were taken 10 minutes apart. The fasting levels of glycine and lysine were low and in keeping with fasting levels reported elsewhere. There was no detectable peak in the position of glycyl-lysine on the chromatogram. After a 10-minute absorption period, most of the dipeptide had disappeared from the lumen.

Portal blood at the end of this period showed very high glycine and lysine levels, and there was again no evidence of glycyl-L-lysine. The concentration of

\begin{tabular}{|c|c|c|c|c|c|c|c|c|}
\hline \multirow{3}{*}{$\begin{array}{l}\text { Jejunum } \\
\text { Initial dipeptide concentration }(\mu \mathrm{Mol} / \mathrm{ml}) \\
\text { Final dipeptide concentration }(\mu \mathrm{Mol} / \mathrm{ml}) \\
\text { Portal Blood }\end{array}$} & \multicolumn{4}{|c|}{ Subject I } & \multicolumn{4}{|c|}{ Subject 2} \\
\hline & \multicolumn{4}{|l|}{$\begin{array}{l}4 \cdot 2 \\
0.95\end{array}$} & \multicolumn{4}{|l|}{$\begin{array}{l}4 \cdot 2 \\
0.47\end{array}$} \\
\hline & Lysine & Glycine & Dipeptide & Valine & Lysine & Glycine & Dipeptide & Valine \\
\hline $\begin{array}{l}\text { Initial blood levels }(\mu \mathrm{Mol} / \mathrm{ml}) \\
\text { Final blood levels }(\mu \mathrm{Mol} / \mathrm{ml})\end{array}$ & $\overline{0.75}$ & $\overline{0.7}$ & $\overline{0}$ & $\overline{0 \cdot 18}$ & $\begin{array}{l}0.14 \\
0.65\end{array}$ & $\begin{array}{l}0.13 \\
0.58\end{array}$ & $\begin{array}{l}\mathbf{0} \\
\mathbf{0}\end{array}$ & $\begin{array}{l}0 \cdot 17 \\
0 \cdot 17\end{array}$ \\
\hline
\end{tabular}

Table I Concentrations of L-lysine and glycine in portal venous radical blood together with those of $\mathrm{L}-\mathrm{valine}$ an amino acid not present in the lumen during closed loop glycyl-L-lysine absorption in the two subjects 
other amino acids, eg, valine (Table I) did not increase, indicating that the lysine and glycine appearing in the portal blood was derived from the intraluminal lysyl-glycine.

\section{Discussion}

Absorption of free amino acids is more rapid from a protein hydrolysate than from an equivalent mixture of free amino acids (Crampton, Gangolli, Simson, and Matthews, 1971). These and other data suggest that intact dipeptide absorption probably plays a significant role in the absorption of dietary protein. Absorption of only a limited number of dipeptides has been studied in man, and even fewer have been studied by the type of quantitative technique employed in the present study (Adibi, 1971; Hellier et al, 1972).

Evidence for intact transport of glycyl-glycine has been obtained by oral load tests in man (Craft et al, 1968), by in-vitro studies (Newey and Smyth, 1962), and by measuring absorption from tied loops of small rat intestine (Matthews, Craft, Geddes, Wise, and Hyde, 1968). Our results support the observations of other workers that the dipeptide is transported intact from the lumen. The second dipeptide, glycyl-L-alanine, has not previously been studied in man. The fact that both glycine and alanine are absorbed faster from the dipeptide than from the mixture in every subject studied is strong evidence that this dipeptide is also transported from the lumen. Where the constituent amino acids were studied separately, alanine was absorbed more rapidly than glycine, as has been observed previously (Fleshler et al, 1966). This difference was not seen when the amino acids were presented as the dipeptide. The loss of the differential absorption rates of the free amino acids when perfused as a dipeptide is further evidence that the dipeptide is being handled differently and probably being transported intact. When free glycine and L-alanine were perfused together, there was no inhibition of absorption of one by the other, in contrast to the results reported by Fleshler et al (1966). This is no doubt because in our experiments both amino acids were perfused at much lower concentrations.

During absorption of these dipeptides, free amino acid appeared within the lumen. Incubation of each dipeptide with fresh jejunal juice for 15 minutes showed no evidence of hydrolysis, so that we can conclude that these free amino acids represent back diffusion of amino acids from the mucosa.

In tied loops of rat intestine, Matthews et al (1968) found less than $1 \%$ of the glycine introduced as glycyl-glycine appearing in the lumen, and enzyme studies on human mucosa demonstrate only very low activity of glycyl-glycine hydrolase (Heizer and Laster, 1969). The free glycine measured during our own studies of glycyl-glycine absorption was greater than this but at no stage exceeded $7 \%$ of the total glycine perfused as dipeptide in the initial solution, at either concentration. Nixon and Mawer (1970), studying hydrolysis of ingested milk protein in jejunal contents by jejunal fluid, found peptides of glycine were only very slowly hydrolysed and suggested on the basis of their studies that one would have to postulate a mode of transport other than the free amino acid pathway to account for the observed rates of glycine absorption. Their observations are in keeping with evidence for intact dipeptide transport and support the concept that the free glycine detected in the lumen represents back diffusion from the mucosa after dipeptide absorption, rather than luminal hydrolysis.

Again, during perfusion of glycyl-L-alanine in no case did the amount of free alanine and glycine represent more than $5 \%$ of the amino acid presented initially as dipeptide. It is of interest that in all subjects studied, glycine appeared in the lumen at more than twice the concentration of alanine. There are two possible explanations for the difference. Either these amino acids diffuse back at different rates into the lumen, or they are recaptured by amino acid transport mechanisms at different rates. The more likely explanation for the difference is in the recapture rate. Alanine has been shown to be much more rapidly absorbed than glycine from the lumen both in our study and in that of Fleshler et al (1966) using much higher concentrations. After back diffusion to the lumen, alanine would be more efficiently recaptured than glycine due to its greater affinity for the transport mechanism. This is consistent with observations made during the absorption of glycyl-L-lysine (Hellier et al, 1972). Much more lysine appeared in the lumen of cystinuric subjects than of control subjects, probably due to failure of lysine recapture in subjects with defective lysine absorption.

The precise site of dipeptide hydrolysis remains uncertain. It could occur on or within the cell membrane, after transport from the lumen, or as an integral part of the transport process. It might well occur actually within the cell or possibly after absorption into the blood stream. In the present study, we have looked for evidence of intact dipeptide transport into the portal blood using the dipeptide glycyl-L-lysine. Although large quantities of the constituent amino acids were detected in the portal blood, there was no evidence of intact dipeptide transport. It is possible therefore to say that as far as glycyl-L-lysine is concerned, this dipeptide is transported intact from the lumen of the intestine, 
hydrolysed somewhere deep to the transport mechanism, but does not cross the mucosa to enter the blood stream intact. The anatomical site of hydrolysis remains unknown, but it is such that free amino acid can leak back into the lumen, from which it is 'recaptured' fairly efficiently by the L-amino acid active transport systems.

It seems likely that different dipeptides are handled in different ways (Fern, Hider, and London, 1969; Nixon and Mawer, 1970; Hellier et al, 1972) and it is therefore not possible to generalize from experience based on any single dipeptide. However, the evidence available so far suggests that with certain exceptions intact dipeptides do not enter the blood stream. Enzymatic studies have shown that $90-95 \%$ of dipeptidase activity occurs within the cell, while 10 to $65 \%$ of tripeptidase activity is localized to the brush border (Peters, 1970). It has been suggested as a result of these data that tripeptides are hydrolysed at the brush border before transport and that dipeptides are hydrolysed after transport into the cell (Peters and MacMahon, 1970). The picture is undoubtedly not as simple as this. Although quantitative data of this type are in favour of intact dipeptide transport, qualitative assessment of the dipeptidases present is necessary before definite conclusions can be drawn. It is quite possible that the small proportion of dipeptidase activity detected in the brush border preparation contains the specific dipeptidases necessary for hydrolysis of dietary peptides, while the intracellular dipeptidases are concerned solely with non-specific cell metabolism. In favour of this is the fact that comparative analysis of dipeptidases from cells of different tissues in the body has shown a striking similarity between the intracellular dipeptidase patterns, whereas the brush border dipeptidase pattern was quite different (Kim, Birtwhistle, Kim, and Sleisenger, 1971).

We should like to thank the subjects for their cooperation and the staff of the Metabolic Ward at
St Bartholomew's Hospital, where these investigations were performed.

M. D. Hellier is grateful to the North-East Metropolitan Regional Hospital Board for financial support.

\section{References}

Adibi, S. A. (1971). Intestinal transport of dipeptides in man; relative importance of hydrolysis and intact absorption. J. clin. Invest., 50, 2266-2275.

Asatoor, A. M., Cheng, B., Edwards, K. D. G., Lant, A. F., Matthews, D. M., Milne, M. D., Navab, F., and Richards, A. J. (1970). Intestinal absorption of two dipeptides in Hartnup disease. Gut, 11, 380-387.

Craft, I. L., Geddes, D., Hyde, C. W., Wise, I. J., and Matthews, D. M. (1968). Absorption and malabsorption of glycine and glycine peptides in man. Gut, 9, 425-437.

Crampton, R. F., Gangolli, S. D., Simson, P., and Matthews, D. M. (1971). Rates of absorption by rat intestine of pancreatic hydrolysates of proteins and their corresponding amino acid mixtures. Clin. Sci., 41, 409-417.

Fern, E. B., Hider, R. C., and London, D. R. (1969). The sites of hydrolysis of dipeptides containing leucine and glycine by rat jejunum in vitro. Biochem. J., 114, 855-861.

Fleshler, B., Butt, J. H., and Wismar, J. D. (1966). Absorption of glycine and L-alanine by the human jejunum. $J$. clin. Invest., 45, 1433-1441.

Heizer, W. D., and Laster, L. (1969). Peptide hydrolase activities of the mucosa of human small intestine. J. clin. Invest., 48, 210 . 228.

Hellier, M. D., Holdsworth, C. D., Perrett, D. and Thirumalai, C. (172). Intestinal dipeptide transport in normal and cystinuric subjects. Clin. Sci., 43, 659-668.

Hellier, M. D., Perrett, D., and Holdsworth, C. D. (1970). Dipeptide absorption in cystinuria. Brit. med. J., 4, 782-783.

Hydén, S. (1955). A turbidimetric method for the determination of higher polyethylene glycols in biological materials. $K$. LantbrHögsk. Annlr., 22, 139-146.

Kim, Y. S., Birtwhistle, W., Kim, Y. W., and Sleisenger, M. H. (1971). Intestinal peptide hydrolases: multiple forms of enzymes in cytoplasm and brush border. Gastroenterology, 60,685 .

Matthews, D. M., Craft, I. L., Geddes, D. M., Wise, I. J., and Hyde, C. W. (1968). Absorption of glycine and glycine peptides from small intestines of rat. Clin. Sci., 35, 415-424.

Newey, H., and Smyth, D. H. (1960). Intracellular hydrolysis of dipeptides during intestinal absorption. J. Physiol. (Lond.), 152, 367-380.

Nixon, S. E., and Mawer, G. E. (1970). The digestion and absorption of protein in man. 2. The form in which digested protein is absorbed Brit. J. Nntr., 24, 241-258.

Peters, T. J. (1970). The subcellular localization of di- and tri-peptide hydrolase activity in guinea-pig small intestine. Biochem. J., 120, 195-203.

Peters, T. J., and MacMahon, M. T. (1970). The absorption of glycine and glycine oligopeptides by the rat. Clin. Sci., 39, 811-821. 